\title{
Degradation pathway of CopA, the antisense RNA that controls replication of plasmid R1
}

\author{
Fredrik Söderbom ${ }^{1} \dagger$ and E. Gerhart H. Wagner ${ }^{2}$ \\ Author for correspondence: E. Gerhart H. Wagner. Tel: +4618 673222. Fax: +4618673392. \\ e-mail: gerhart.wagner@mikrob.slu.se
}

\author{
1 Department of \\ Microbiology, Biomedical \\ Center, Uppsala University, \\ Box 581, S-75123 Uppsala, \\ Sweden \\ 2 Department of \\ Microbiology, SLU \\ (Swedish University of \\ Agricultural Sciences), Box \\ 7025, S-75007 Uppsala, \\ Sweden
}

\begin{abstract}
RNA decay in bacteria is carried out by a number of enzymes that participate in the coordinated degradation of their substrates. Endo- and exonucleolytic cleavages as well as polyadenylation are generally involved in determining the half-life of RNAs. Small, untranslated antisense RNAs are suitable model systems to study decay. A study of the pathway of degradation of CopA, the copy number regulator RNA of plasmid R1, is reported here. Strains carrying mutations in the genes encoding RNase E, polynucleotide phosphorylase (PNPase), RNase II and poly(A) polymerase I (PenB/PAP I) - alone or in combination - were used to investigate degradation patterns and relative halflives of CopA. The results obtained suggest that RNase $E$ initiates CopA decay. Both PNPase and RNase II can degrade the major 3'-cleavage product generated by RNase E. This exonucleolytic degradation is aided by PenB, which may imply a requirement for A-tailing. RNase II can partially protect CopA's 3'-end from PNPase-dependent degradation. Other RNases are probably involved in decay, since in rnb/pnp double mutants, decay still occurs, albeit at a reduced rate. Experiments using purified RNase E identified cleavage sites in CopA in the vicinity of, but not identical to, those mapped in vivo, suggesting that the cleavage site specificity of this RNase is modulated by additional proteins in the cell. A model of CopA decay is presented and discussed.
\end{abstract}

Keywords: antisense RNA, RNA decay, RNase E, exoribonucleases, poly(A) polymerase

\section{INTRODUCTION}

RNA degradation in bacteria is a complex process. Structure and sequence elements in mRNAs are known to determine the stability of individual RNAs. Half-lives from $<1 \mathrm{~min}$ to $>50 \mathrm{~min}$ have been measured, but the motifs that govern these great differences in stability are only poorly understood. A great number of RNases have been identified (Deutscher, 1993). Most of them have roles in the processing of stable RNAs, but some are clearly involved in the degradation of mRNAs. Recent work indicated that RNA decay occurs by the concerted activity of a number of physically associated proteins, collectively referred to as the degradosome (Carpousis $e t$ al., 1994; Py et al., 1996; Miczak et al., 1996). In

†Present address: Department of Biology, University of California at San Diego, 9500 Gilman Drive Dept 0368, La Jolla, CA 92093-0368, USA.

Abbreviations: FL-CopA, full-length CopA; PNPase, polynucleotide phosphorylase; SL-E, RNase-E-generated 3'-stem-loop of CopA containing a $5^{\prime}$-tail. addition to the endoribonuclease RNase $\mathrm{E}$ and the $3^{\prime} \rightarrow 5^{\prime}$-exonuclease polynucleotide phosphorylase (PNPase), additional proteins were shown to be part of this complex: the $\beta$-subunit of PNPase (enolase, a glycolytic enzyme), an RNA helicase possibly involved in disruption of RNA structure (RhlB) and the heat-shock protein and chaperonin DnaK. The chaperonin GroEL was found associated with this complex under some conditions (Miczak et al., 1996; see also Sohlberg et al., 1993). The significance of this latter finding is not clear, but recent work has demonstrated that purified GroEL can protect RNA from degradation in vitro (Georgellis et al., 1995). Finally, a protein that may protect stem-loops from 3'-exonucleolytic degradation (EIF) also co-purifies with RNase E and PNPase (Py et al., 1994). The recent establishment of an in vivo-like in vitro mRNA degradation system suggested that degradosomal components are polysomally located (Ingle \& Kushner, 1996). Interestingly, an additional enzyme involved in RNA decay, the poly(A) polymerase $\mathrm{PcnB} /$ PAP I (Lopilato et al., 1986; Cao \& Sarkar, 1992), has 
previously been found associated with polysomes as well (Ingle \& Kushner, 1996). Hence, although this enzyme has not yet been found stably associated with the degradosome, it may be located at/near the site where degradation occurs.

Antisense RNAs are suitable models for the study of RNA decay, since they are (i) small and untranslated, (ii) generally well-characterized with respect to structure and biological function and (iii) easily manipulated in vitro. We have previously characterized replication control of plasmid R1 and studied the structure and function of the replication control element, the antisense RNA CopA (Wagner \& Nordström, 1986; for reviews see Wagner \& Simons, 1994; Nordström \& Wagner, 1994). CopA inhibits replication of plasmid R1 by binding to the target region, CopT, within the repA mRNA, to block the synthesis of the replication initiator protein RepA. In almost all cases, copy number regulator RNAs are constitutively synthesized and rapidly turned over (for an exception see Brantl \& Wagner, 1996). Hence, rapid decay is a hallmark of CopA as well as of RNA I, the antisense RNA controlling the replication of plasmid ColE1 (Eguchi et al., 1991). The decay of both RNAs is initiated by RNase E cleavage, which is a prerequisite for rapid subsequent degradation (LinChao \& Cohen, 1991; Söderbom et al., 1997). Previous work also showed that the PcnB protein is needed for normal decay of these RNAs, and that RNase-Egenerated cleavage products are stabilized in its absence (Xu et al., 1993; He et al., 1993; Söderbom et al., 1997). Xu \& Cohen (1995) presented evidence that the PcnBdependent addition of adenosines to the 3 '-end of RNA I creates a substrate for PNPase and is required for decay. The question of whether or not CopA also requires A-tails for decay is not yet settled (Söderbom $\boldsymbol{e t}$ al., 1997). The PcnB-dependence of RNA I and CopA degradation is different: in $p c n B$ mutant strains, RNA I was stabilized more than tenfold (Xu et al., 1993; He et al., 1993), whereas only a twofold effect was seen for CopA (Söderbom et al., 1997).

In an attempt to characterize the pathway of CopA decay in more detail, we used strains carrying mutant alleles of $r n e$ (encoding RNase E), pnp (PNPase), $r n b$ (RNase II) or $p c n B$ (PcnB/PAP I). Single and multiple mutant strains were constructed, and CopA accumulation and degradation patterns were analysed. The effect of the mutations present on the degradation of CopA was analysed by rifampicin run-out experiments. RNase E cleavage sites in CopA were mapped in vitro and compared to those previously identified in vivo (Söderbom et al., 1997). Finally, we compared relative cleavage rates of RNase E on CopA and RNA I substrates in vitro and found that RNA I is more rapidly processed. Based on the results obtained, we discuss a tentative pathway of CopA decay.

\section{METHODS}

Bacterial strains and plasmids. The Escherichia coli strains used in this study are shown in Table 1 . To introduce the $p c n B$ deletion, we used P1 transduction as described by Söderbom $e t$ al. (1997). For the experiments reported, cells were grown in $L$ broth (Bertani, 1951) supplemented with $50 \mu \mathrm{g}$ kanamycin $\mathrm{ml}^{-1}$ for $\Delta p c n B$ strains. All strains containing the rne-1/ams-1 mutation were grown in the presence of $50 \mu \mathrm{g}$ thymine $\mathrm{ml}^{-1}$. Growth of bacteria was at $30^{\circ} \mathrm{C}$ unless otherwise indicated. Plasmid pKG339 (Jensen et al., 1995) is a pSC101 replicon carrying a $\operatorname{cop} A$ gene under the control of an IPTG-inducible promoter. When plasmid pKG339 was present, the medium contained $15 \mu \mathrm{g}$ tetracycline $\mathrm{ml}^{-1}$.

Analysis of CopA patterns in vivo by Northern analysis. Strains containing plasmid pKG339 were grown at $30^{\circ} \mathrm{C}$, and at an $\mathrm{OD}_{600}$ of about $0 \cdot 2$, half of the culture was transferred to $44^{\circ} \mathrm{C}$ for $20 \mathrm{~min}$. IPTG was added to $1 \mathrm{mM}$ to all cultures, and samples were collected for RNA extraction after an additional $10 \mathrm{~min}$. RNA preparation and Northern blot analyses were performed as described by Söderbom et al. (1997). The probe for CopA RNA was in vitro transcribed, uniformly $\left[\alpha^{32}\right.$ P]UTP-labelled CopT RNA (Hjalt \& Wagner, 1995).

Decay of CopA in strains carrying mutations in genes encoding RNases and/or PcnB. Cell growth was the same as above, except that rifampicin (Sigma) was added to $0.2 \mathrm{mg}$ $\mathrm{ml}^{-1} 10 \mathrm{~min}$ after IPTG induction of CopA transcription. Subsequently, aliquots were withdrawn at intervals for Northern blot analysis. Decay rates were calculated from semi-logarithmic plots based on PhosphorImager analysis of Northern blots. Corrections for loading were done by probing for 5S rRNA as described by Söderbom et al. (1997).

In vitro cleavages of CopA by RNase E. Cleavages were performed either on $5^{\prime}$-end-labelled CopA $(\sim 0.4 \mathrm{pmol}$; generated by phosphorylation of in vitro transcribed CopA; Hjalt \& Wagner, 1995) or of ${ }^{3} \mathrm{H}$-labelled CopA ( $\left.~ 0.1 \mathrm{pmol}\right)$, in a buffer containing $10 \mathrm{mM}$ Tris/ $\mathrm{HCl}, \mathrm{pH} 7.9,5 \mathrm{mM} \mathrm{MgCl}$, $0.1 \mathrm{mM}$ DTT and $100 \mathrm{mM} \mathrm{NH}_{4} \mathrm{Cl}$. Purified RNase E (Naureckiene \& Uhlin, 1996) was a generous gift from Saule Naureckiene (Microbiology Dept, University of Umeå). Cleavages were performed in $40 \mu \mathrm{l}$ reaction mixtures. The amount of enzyme added was tested in pilot experiments to obtain suitable time intervals. In the case of end-labelled CopA (experiment in Fig. 4), $4 \mu \mathrm{l}$ aliquots were quenched in gel loading buffer containing $7 \mathrm{M}$ urea. After heating for $3 \mathrm{~min}$ at $85^{\circ} \mathrm{C}$, the samples were loaded onto $8 \%$ sequencing gels. The dried gels were autoradiographed using Kodak X-Omat S or Amersham Hyperfilm MP.

In the case of unlabelled CopA, reactions were stopped by withdrawing aliquots at different times into phenol. After phenol extraction, the RNA was precipitated in the presence of $10 \mu \mathrm{g}$ glycogen, redissolved in water, and subsequently reverse transcribed as in Söderbom et al. (1997). The cDNA products were electrophoresed on $8 \%$ sequencing gels. Sequencing ladders generated on $\operatorname{copA}$ DNA using the same primer were used as markers.

Relative cleavage activity of RNase E on CopA and RNA I substrates in vitro. CopA and RNA I $\left(0.2\right.$ pmol each, both $5^{\prime}$ phosphorylated by $\left[\gamma^{32} \mathrm{P}\right] \mathrm{ATP}$ and T4 polynucleotide kinase) were mixed in RNase E buffer (see above). RNase E was added, and aliquots were quenched in stop buffer as above, followed by gel analysis and autoradiography. Quantification of RNA I and CopA band intensities on the dried gel was performed using a Molecular Dynamics PhosphorImager $400 \mathrm{~S}$.

Oligodeoxyribonucleotides. The oligodeoxyribonucleotide used for primer extension analysis was FRED 53: 5'-AAA CCC CGA TAA TCT TCT TCA ACT TT-3'. 
Table 1. Bacterial strains

\begin{tabular}{|c|c|c|}
\hline Strain & Relevant genotype & Source/reference \\
\hline SK 5665 & $r n e-1$ ( = ams-1, temperature sensitive) thyA715 $\mathrm{F}^{-}$ & Arraiano et al. (1988) \\
\hline SK 5671 & rne-1 pnp-7 tbyA715 $\mathrm{F}^{-}$ & Arraiano et al. (1988) \\
\hline SK 5715 & rne-1 rnb-500 (temperature sensitive) thy A715 $\mathrm{F}^{-}$ & Arraiano et al. (1988) \\
\hline SK $5704 \Delta p c n B$ & $r n e-1$ pnp-7 rnb-500 $\Delta p c n B$ thyA715 $\mathrm{F}^{-}$ & This work \\
\hline SK $5715 \Delta p c n B$ & $r n e-1 r n b-500 \Delta p c n B$ thyA715 $\mathrm{F}^{-}$ & This work \\
\hline NDM 5003 & pnp-7 rnb-500 thr leu $\mathrm{F}^{-}$ & $\begin{array}{l}\text { K. Gerdes, Odense } \\
\text { University, Denmark* } \\
\text { (unpublished) }\end{array}$ \\
\hline NDM $5003 \Delta p c n B$ & $p n p-7 r n b-500 \Delta p c n B$ thr leu $\mathrm{F}^{-}$ & This work \\
\hline NDM 5004 & pnp-7 thr leu $\mathrm{F}^{-}$ & K. Gerdes ${ }^{*}$ (unpublished) \\
\hline NDM $5004 \Delta p c n B$ & $p n p-7 \Delta p c n B$ tbr leu $\mathrm{F}^{-}$ & This work \\
\hline NDM 5005 & $r n b-500$ (temperature sensitive) thr leu $\mathrm{F}^{-}$ & K. Gerdes* (unpublished) \\
\hline NDM $5005 \Delta p c n B$ & rnb-500 $\Delta p c n B$ thr leu $\mathrm{F}^{-}$ & This work \\
\hline NDM 5006 & thr leu $\mathrm{F}^{-}$ & K. Gerdes* (unpublished) \\
\hline NDM $5006 \Delta p c n B$ & $\Delta p c n B$ thr leu & This work \\
\hline
\end{tabular}

* These strains correspond to the SK strain series (Donovan \& Kushner, 1986) but were cured from a plasmid carrying an additional copy of the $r n b-500$ allele.

Enzymes and chemicals. Chemicals and enzymes were purchased from Amersham or Sigma unless otherwise stated. Radioactive ribonucleotides were purchased from DuPont/ New England Nuclear.

\section{RESULTS}

\section{Involvement of RNase E, PNPase, RNase II and PcnB in the degradation of CopA in vivo}

For this study, we constructed isogenic strains carrying mutations in either one of the genes encoding these four enzymes, alone and in combinations (Table 1; see Methods for details). The mutations in rne (ams-1/rne1) and $r n b(r n b-500)$ are alleles conferring temperature sensitivity (Donovan \& Kushner, 1986). The point mutation in the $p n p$ gene (pnp-7) almost completely abolishes activity (Donovan \& Kushner, 1986). The $p c n B$ mutation used is a deletion of most of its gene (Masters et al., 1993).

Plasmid pKG339 (Jensen et al., 1995) was chosen as the carrier of the $\operatorname{cop} A$ gene for the following reasons. An IPTG-inducible promoter replaces the authentic copA promoter. Thus, CopA synthesis can be induced after temperature shifts in strains carrying the temperaturesensitive alleles mentioned above. The use of such a protocol implies that the newly synthesized CopA has never encountered these (active) enzymes. In addition, the absence of the repA promoter on $\mathrm{pKG} 339$ prevents transcription of CopT RNA. This is of importance, since CopT, if present, will bind to CopA, entailing RNase III cleavage (Blomberg et al., 1990) and, possibly, the protection of CopA segments. Finally, the backbone of pKG339 is derived from plasmid pSC101, whose copy number is not controlled by an antisense RNA. This is

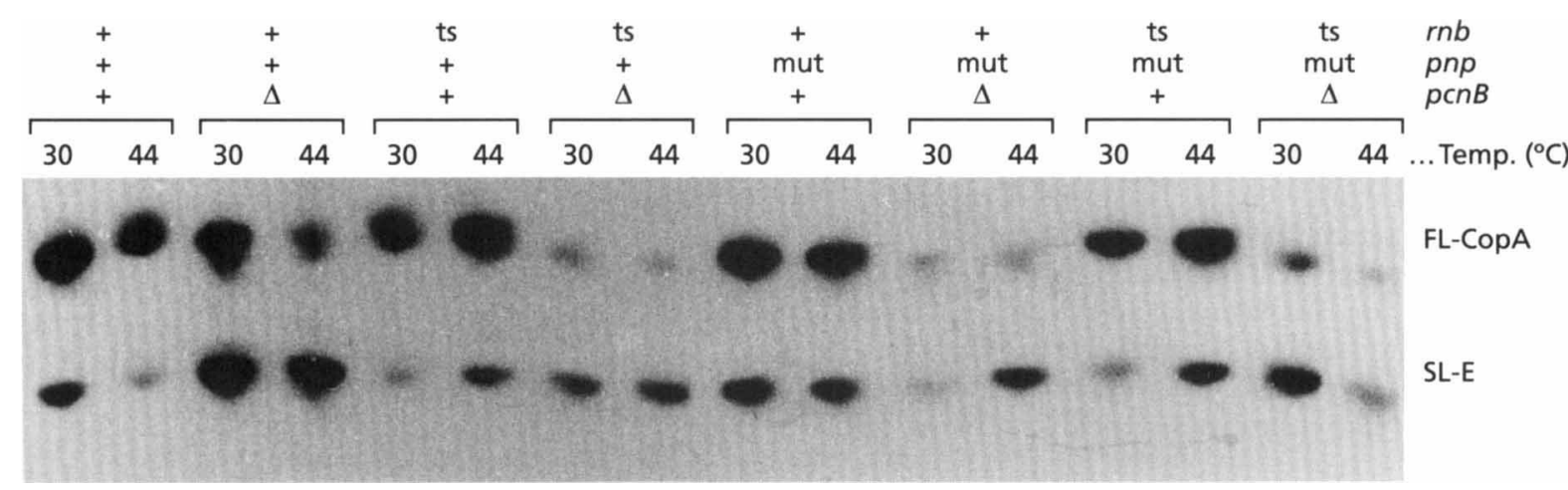

Fig. 1. CopA patterns in strains with combinations of $r n b$, pnp and pcnB mutant alleles. Strains with mutations in $r n b$, pnp and $p c n B$ genes (Table 1) were grown at permissive temperature or shifted to non-permissive temperature. CopA synthesis was induced by IPTG from plasmid pKG339 and Northern blot analysis was performed as described in Methods. The figure shows an autoradiogram of such an analysis. The state of the different alleles is indicated by $\Delta, \mathrm{ts}, \mathrm{mut}$ or + . 


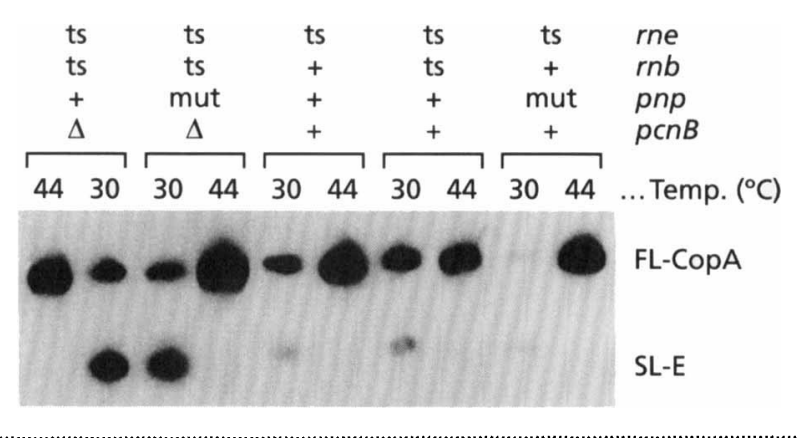

Fig. 2. CopA patterns in strains with combinations of $r n e, r n b$, pnp and pCnB mutant alleles. Strains with mutations in rne, $r n b, p n p$ and pcnB genes (Table 1) were grown at permissive temperature or shifted to non-permissive temperature. The analysis and labelling of the lanes was as in Fig. 1.

particularly useful in strains carrying $p c n B$ mutations that were shown to affect the copy numbers of R1 and ColE1 (see above).

Two sets of experiments were performed. Figs 1 and 2 represent analyses of CopA patterns on Northern blots in the presence and absence of active enzymes. In all cases and with all combinations of mutations, cells were grown at permissive temperature or shifted to nonpermissive temperature before induction of CopA synthesis. The experiments shown in Fig. 3 are rifampicin run-outs. For easy comparison, the same time points were chosen in all experiments (Fig. 3a-j). Table 2 shows the half-life values obtained from the same experiment. Due to the absence of CopT the general pattern of CopA bands is simple: the upper band represents full-length CopA (FL-CopA), and the lower band the RNase-E-generated 3'-stem-loop of CopA containing a $5^{\prime}$-tail (SL-E; Söderbom et al., 1997). An interpretation of the effects of the individual mutations and their contribution to the decay pathway is given below.

\section{RNase E}

In line with previous results, inactivation of $\mathrm{RNase} \mathrm{E}$ results in stabilization of FL-CopA, irrespective of any of the other activities present (Figs 2 and $3 \mathrm{~b}, \mathrm{f}$; Table 2; Söderbom et al., 1997). This indicates that RNase E is the only enzyme responsible for this cleavage, and that the initial cut is required for subsequent degradation. At permissive temperature, RNase E cleaves CopA irrespective of the presence and absence of the three other activities. This suggests that RNase $\mathrm{E}$ is not dependent on these enzymes for cleavage site selection or activity. The absence of additional degradation intermediates that were detected previously (Söderbom et al., 1997) is tentatively explained by the absence of CopT in the cell.

\section{PenB}

Mutations in $p c n B$ had previously been shown to increase the stability of SL-E (Söderbom et al., 1997), whereas FL-CopA was not affected, indicating that its activity is required only subsequent to $\mathrm{RNase} E$ cleavage. In all strains carrying a wild-type $p c n B$ allele, FL-CopA was more abundant than SL-E (Figs 1-3; Table 2), and the $p c n B$ mutation reversed the relative band intensities. Hence, the effect of $P c n B$ is apparent both in the presence and absence of the other enzymic activities. We also note that the patterns observed do not indicate a significant extent of PcnB-dependent addition of adenosines, since the migration of both CopA bands appears unaffected by $\mathrm{PcnB}$.

\section{Exoribonucleases PNPase and RNase II}

A mutation in the pnp gene showed remarkably small effects on the band patterns or the degradation rate of SL-E (Fig. 1, cf. lanes 1, 2 and 9, 10; Fig. 3d). PNPase is apparently unable to degrade FL-CopA, since in an rne mutant strain at non-permissive temperature, FL-CopA is stable (Fig. 2; Fig. $3 \mathrm{~b}, 44^{\circ} \mathrm{C}$ ). So far, the similarity of band patterns and CopA half-lives in the presence or absence of PNPase suggests that RNase II (or possibly other enzymes) can functionally replace PNPase on an SL-E substrate or that PNPase normally is not involved (but see below).

Upon inactivation of RNase II alone, a small but significant destabilization of SL-E is seen (e.g. Fig. 3c). This may suggest that active RNase II can protect SL-E from PNPase-dependent degradation, and that this protection is lost upon inactivation of RNase II (Fig. 3c, cf. 30 and $44^{\circ} \mathrm{C}$; Table 2). In the $r n b / p n p$ double mutant strain at non-permissive temperature, SL-E is significantly stabilized (Fig. 3g) and persists for longer than $5 \mathrm{~min}$. Thus, the relatively small effects of single $p n p / r n b$ mutations on the decay rate of SL-E on the one hand, and the significant effect in the double mutant strain on the other, indicate that either of these enzymes can functionally substitute for the other. The lack of complete stabilization of SL-E in the $\mathrm{Exo}^{-}$strain at nonpermissive temperature suggests that other RNases can replace RNase II and PNPase, although with reduced efficiency.

As indicated above, the most dramatic stabilization of SL-E is always associated with a $p c n B$ lesion, i.e. SL-E is more stable in an $\mathrm{Exo}^{+} / \triangle p c n B$ strain than in an $\mathrm{Exo}^{-} / p c n B^{+}$strain. The degree of stabilization in the absence of PcnB is only slightly affected by the activities of RNase II and PNPase. When the decay of SL-E was followed after rifampicin treatment in the presence or absence of PNPase, RNase II or both, only a minor additional stabilization of SL-E was seen (Fig. 3e, h, i, j; and F. Söderbom, unpublished). We conclude that both exonucleases require $\mathrm{PcnB}$ or polyadenylation for their proper activities.

\section{RNase E cleaves CopA at two major sites in vitro}

In a recent publication, we showed that RNase-Edependent cleavage of CopA in vivo generates SL-E, and that the cleavage site was located within a single- 
(a)

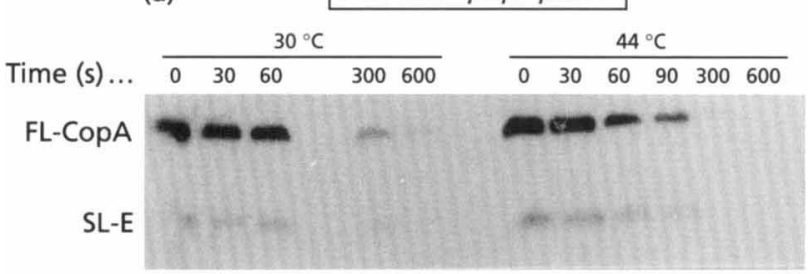

(c) $r n e^{+} r n b(t s) p n p^{+} p c n B^{+}$

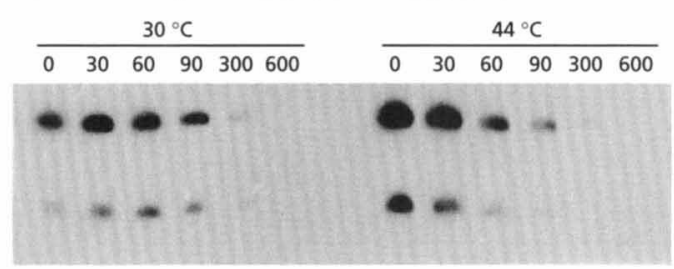

(e)

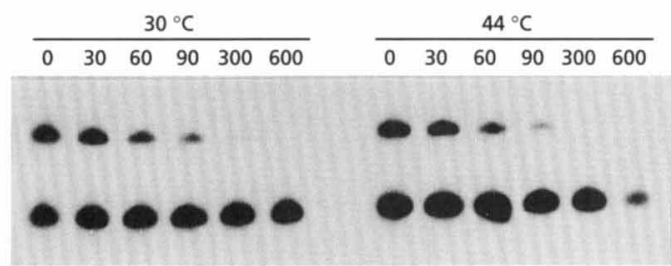

(g)

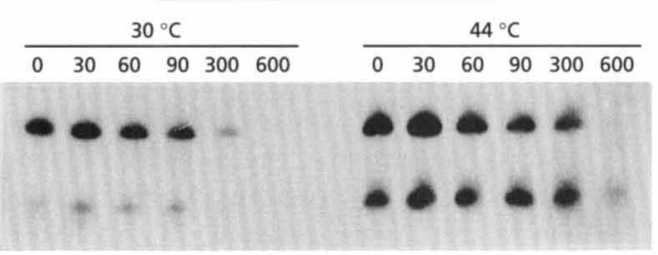

(i)

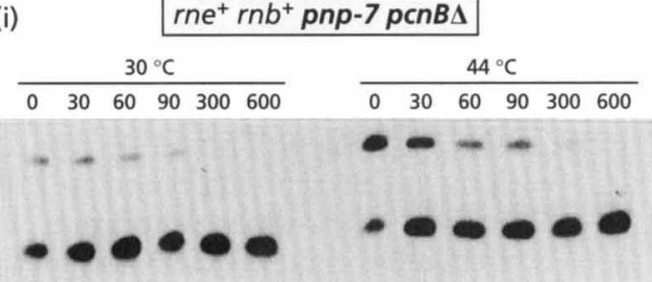

(b) rne(ts) $r n b^{+} p n p^{+} p c n B^{+}$

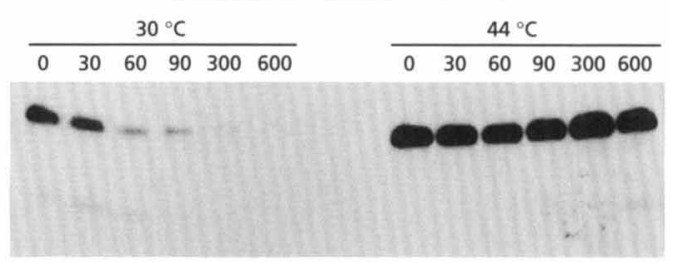

(d)

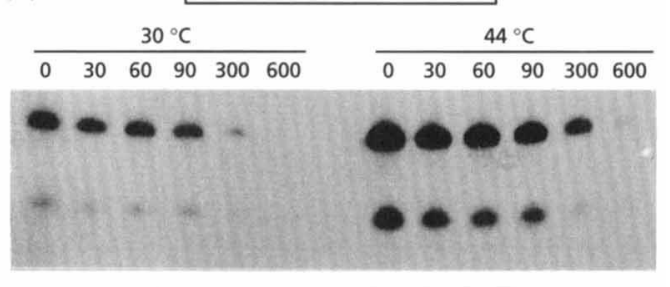

(f)

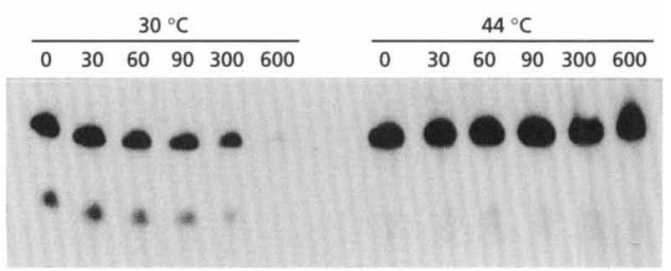

(h)

$r n e^{+} r n b(t s) p n p^{+} p c n B \Delta$

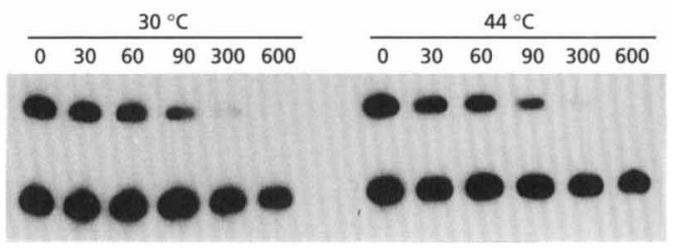

(j)

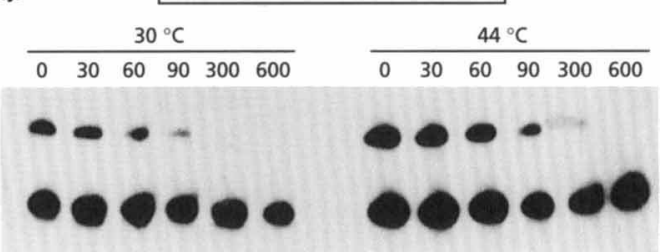

Fig. 3. Time courses of CopA decay in different mutant strain backgrounds. The protocol for this experiment is described in Methods. After addition of rifampicin, aliquots of the cultures were withdrawn for Northern blot analysis. Temperatures and time of sampling are indicated. The positions of FL-CopA and SL-E are indicated in (a). (a)-(j) represent experiments in the different strain backgrounds. The relevant genotypes are boxed, and the mutated alleles are indicated in bold. A quantification of this experiment is given in Table 2 .

stranded region between the two CopA stem-loops (Söderbom et al., 1997). The exact $5^{\prime}$-end of SL-E in vivo was mapped within the sequence GG $\Downarrow$ UUUAA; the arrow indicates the position of cleavage. Since other proteins that could affect cleavage site selection are present in vivo, we tested for cleavage of $5^{\prime}$-end-labelled CopA using purified RNase $\mathrm{E}$ in vitro. Fig. 4 shows an autoradiogram of such an analysis. CopA was cleaved to generate two major 5 -fragments, here denoted $\mathrm{E} / 1$ and $\mathrm{E} / 2$. Their band intensities, determined by Phospor-
Imager analysis, do not indicate a precursor-product relationship, i.e. cleavage by purified RNase E can occur at two sites with almost equal efficiency and rate in vitro. The significance of a third, minor band is unclear: its intensity is much less than that of the others (Fig. 4, '?'). The RNA species generated may stem from secondary cleavage since its appearance is delayed. Since $5^{\prime}$-end-labelled RNA was used in this experiment, the positions of the 3 -ends of the cleavage products could only be estimated from the size of the products. 
Table 2. Decay of CopA in wild-type and mutant strain backgrounds

\begin{tabular}{|c|c|c|c|c|}
\hline \multirow[t]{2}{*}{ Relevant genotype* } & \multicolumn{2}{|c|}{ Half-life at $30^{\circ} \mathrm{C}(\mathrm{s}) \dagger$} & \multicolumn{2}{|c|}{ Half-life at $44^{\circ} \mathrm{C}(\mathrm{s}) \dagger$} \\
\hline & FL-CopA & [SL-E] & FL-CopA & [SL-E] \\
\hline$r n e^{+} r n b^{+} p n p^{+} p c n B^{+}$ & 50 & [73] & 58 & {$[61]$} \\
\hline$r n e(t s) r n b^{+} p n p^{+} p c n B^{+}$ & 53 & [ND] & $>300$ & [ND] \\
\hline$r n e^{+} r n b(t s) p n p^{+} p c n B^{+}$ & 55 & {$[80]$} & 32 & [40] \\
\hline$r n e^{+} r n b^{+} p n p-7 p c n B^{+}$ & 56 & [47] & 73 & {$[62]$} \\
\hline$r n e^{+} r n b^{+} p n p^{+} p c n B \Delta$ & 59 & {$[>300]$} & 48 & {$[>300]$} \\
\hline$r n e(t s) r n b(t s) p n p^{+} p c n B^{+}$ & 75 & {$[75]$} & $>300$ & [ND] \\
\hline$r n e^{+} r n b(t s) p n p-7 p c n B^{+}$ & 80 & [ND] & 115 & {$[>300]$} \\
\hline$r n e^{+} r n b(t s) p n p^{+} p c n B \Delta$ & 70 & {$[>300]$} & 56 & {$[>300]$} \\
\hline$r n e^{+} r n b^{+} p n p-7 p c n B \Delta$ & 74 & {$[>300]$} & 60 & {$[>300]$} \\
\hline$r n e^{+} r n b(t s) p n p-7 p c n B \Delta$ & 60 & {$[>300]$} & 61 & {$[>300]$} \\
\hline
\end{tabular}

* Same denotation as in Fig. 3.

†Values derived from the experiment shown in Fig. 3. Relative band intensities were corrected using $5 S$ rRNA loading controls. Values in brackets were intrinsically less reliable since decay of FL-CopA occurs via the SL-E intermediate.

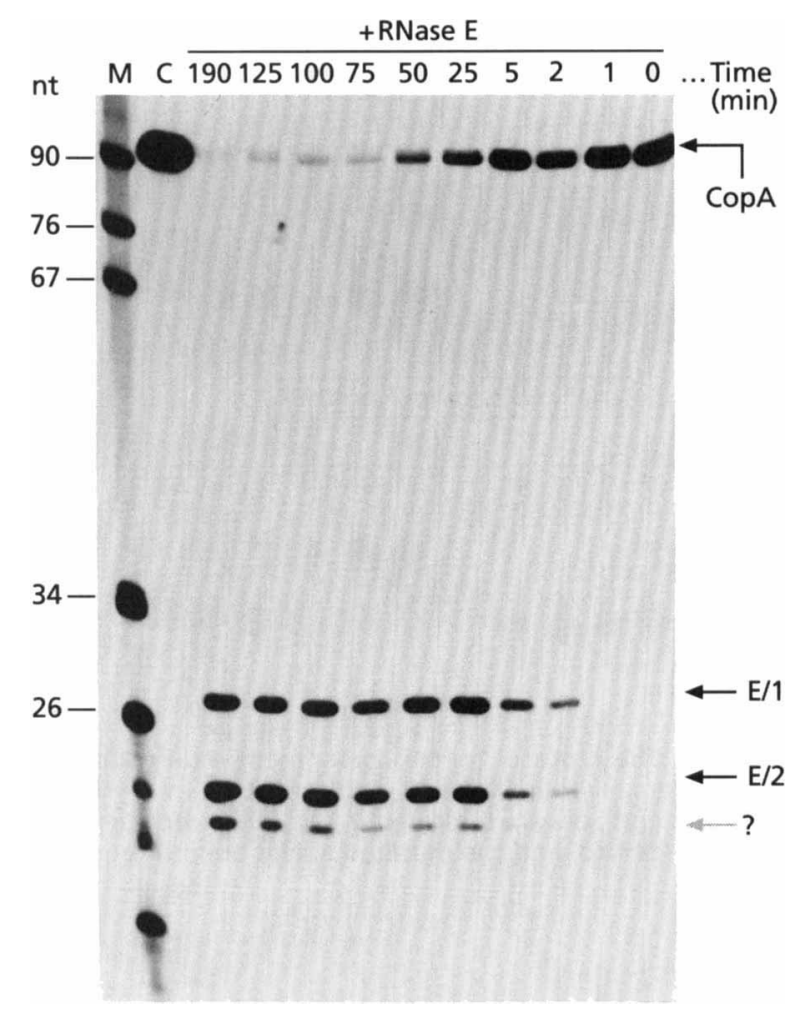

Fig. 4. RNase E cleavage of $5^{\prime}$-end-labelled CopA in vitro. Conditions for cleavage and gel analysis are given in Methods. The figure shows an autoradiogram of the analysis. The times of sample withdrawal are indicated. 'CopA' shows the position of the uncleaved RNA, 'E/1' and 'E/2' represent the two major, RNase-E-cleaved 5'-fragments generated, and '?' is a minor cleavage product (see Results). Lane C shows CopA incubated in the absence of RNase E for $190 \mathrm{~min}$, and the marker lane (M) contains radioactively labelled $\mathrm{Mspl}$-generated DNA fragments of plasmid pBR322.
To analyse the $3^{\prime}$-cleavage products, we performed a similar cleavage test using unlabelled CopA. Aliquots withdrawn from the time course experiment were analysed by reverse transcription to determine the $5^{\prime}$ ends of the cleaved 3'-CopA fragments (see Methods for details). Fig. 5 shows such an analysis. Due to the very stable structure of the $3^{\prime}$-half of CopA, numerous reverse transcription stops are present. One strong such site is indicated by an asterisk. In contrast to this band, whose intensity is unchanged over the time course, two bands increase in intensity and, hence, are due to RNase E cleavage. The exact $5^{\prime}$-ends corresponding to these two RNA fragments can be read off the sequence ladder and are shown in Fig. 6. These $5^{\prime}$-end points are in agreement with the deduced $3^{\prime}$-end points of E/1 and E/2 in Fig. 4 . Therefore, the same denotation is used in Fig. 5. Interestingly, the two cleavage sites are different from the one mapped in vivo (Söderbom et al., 1997; see also Blomberg et al., 1990), indicating that other proteins present in the cell may influence RNase E cleavage site selection in vivo. In summary, the combined results of the experiments shown in Figs 4 and 5 suggest that two major endonucleolytic, RNase-E-dependent, cleavages occur in CopA in vitro. The $5^{\prime}$-fragment represented by the minor band (Fig. 4, '?') may be derived from either $\mathrm{E} / 1$ or $\mathrm{E} / 2$ by exonucleolytic activity present as a minor contaminant in the RNase E preparation.

\section{RNA I is cleaved more rapidly than CopA by purified RNase $\mathrm{E}$ in vitro}

Both RNA I and CopA are substrates for RNase E in vivo and in vitro. The overall in vivo decay rate of CopA is slightly higher than that of RNA I (He et al., 1993; Xu et al., 1993; Söderbom et al., 1997). RNase E is responsible for the initial cleavage step in the decay of 


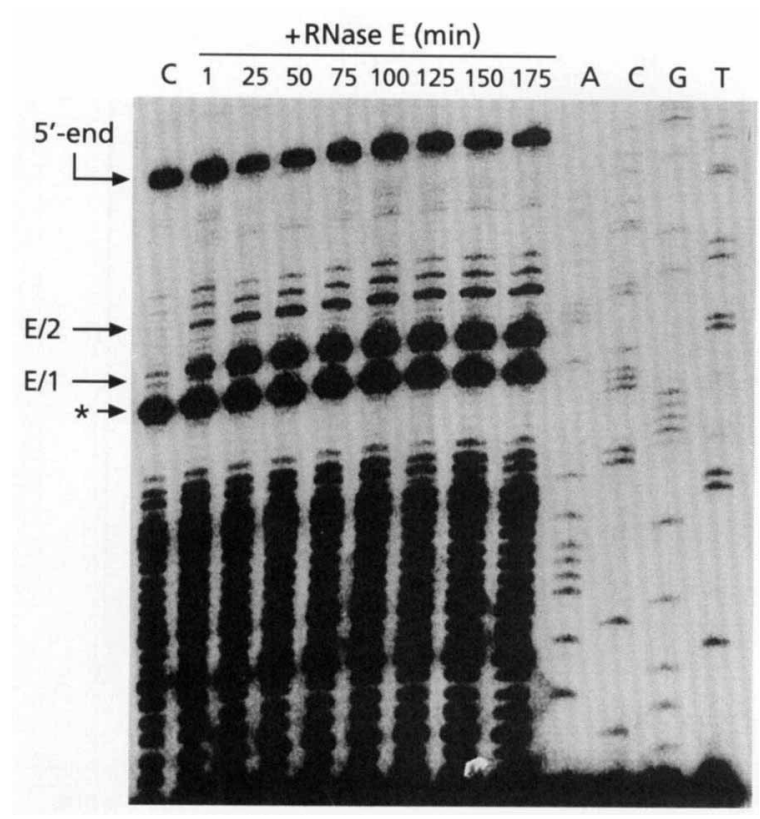

Fig. 5. Determination of 5 '-ends of in vitro RNase-E-cleaved CopA. Conditions for RNase E cleavage of CopA as well as reverse transcription analysis are given in Methods. The times of sample withdrawal are indicated. Lane $C$ shows reverse transcription products generated on CopA incubated for $175 \mathrm{~min}$ in the absence of RNase $E$. The cDNA products corresponding to the $5^{\prime}$-end of CopA and to the two major cleaved species, ' $E / 1$ ' and ' $E / 2$ ', are indicated. The asterisk indicates the position of a strong, structure-dependent and RNase-E-independent, reverse transcription stop. The sequencing ladders $(A, C, G, T)$ were generated using the same primer as the one used for reverse transcription.

both RNAs. We therefore asked whether RNase E acts more rapidly on a CopA substrate than on RNA I. Endlabelled CopA and RNA I were mixed, and RNase E was added to initiate cleavage. Cleavages were followed over a time course of $60 \mathrm{~min}$. Fig. 7(a) shows an autoradiogram of such an experiment and Fig. $7(\mathrm{~b})$ shows a quantification of the ratio of the RNA I/CopA band intensities as a function of time. Clearly, in the competition between these two substrates for RNase E, RNA I is preferred (or more rapidly cleaved). It is worth emphasizing that this experiment was done without addition of other components of the degradosomal machinery, and that the folding of the two RNAs under in vitro conditions may be somewhat different from their structures in vivo.

\section{DISCUSSION}

In this communication, we investigated the involvement of four proteins in the concerted degradation of CopA, the copy number regulator of plasmid $\mathrm{R} 1$. In a previous publication, we showed that CopA decay is initiated by RNase E cleavage, resulting in an extremely unstable $5^{\prime}$ fragment and a 3 '-fragment, SL-E. The latter degradation intermediate is further degraded in a PcnBdependent manner. Here, we extend this analysis by

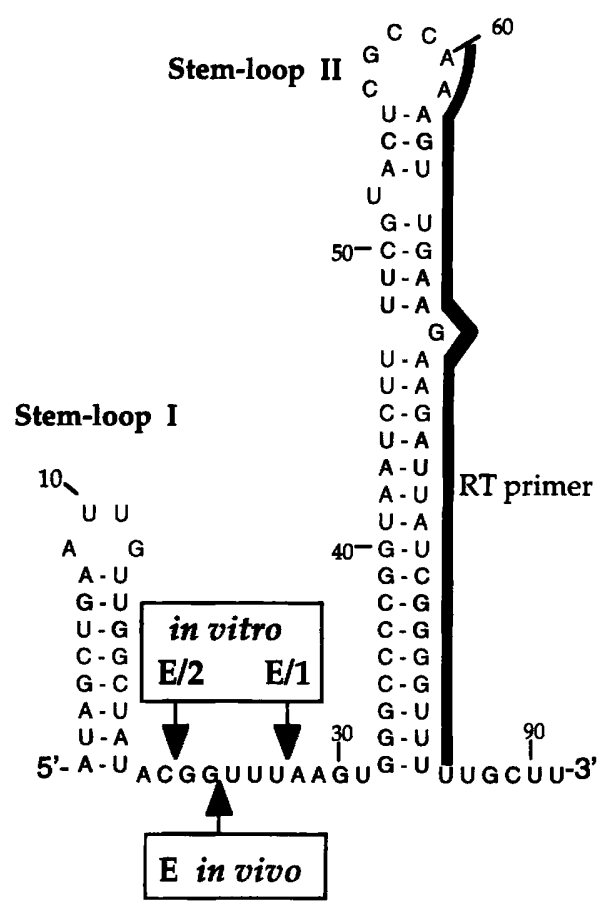

Fig. 6. Localization of in vitro and in vivo RNase E cleavage sites on CopA. The secondary structure of CopA is shown (Wagner \& Nordström, 1986; C. Malmgren and others, unpublished). The in vivo cleavage site mapped previously (Soderbom et al., 1997) and the two major sites identified in vitro (Fig. 5) are indicated. The location of the reverse transcription primer relative to the CopA sequence is shown.

using host strains carrying lesions in the genes encoding RNase II and PNPase. These two exoribonucleases are considered to be the major enzymes with a $3^{\prime} \rightarrow 5^{\prime}$ specificity in $E$. coli. In addition, they have been implicated in mRNA decay (Nierlich \& Murakawa, 1996) as well as in the decay of regulatory RNAs (e.g. RNA-OUT, antisense RNA of IS10; Pepe et al., 1994). The use of multiply mutated strains at both permissive and non-permissive temperature (the $r n b$ and $r n e$ alleles used encode heat-labile proteins) enabled us to compare the CopA degradation patterns (Figs 1 and 2) and the decay of FL-CopA and SL-E after rifampicin addition (Fig. 3; Table 2).

The conclusions from this analysis re-emphasize the key role of $\mathrm{RNase} E$ in mediating the initial cleavage. Irrespective of the presence or absence of any of the other activities, inactivation of RNase $E$ resulted in almost complete stabilization of full-length CopA. The major RNase-E-generated CopA fragment, SL-E, was unstable in the presence of $\mathrm{PcnB}$, but stabilized in its absence. Whether this effect depends on 3'-adenylation cannot be decided based on the experiments reported here but appears likely since a similar but more pronounced PcnB-dependent effect on the decay of RNA I has been shown to be due to polyadenylation (Xu \& Cohen, 1995). A recent publication from the Gerdes group also shows that the rapid degradation of Sok, the 
(b)
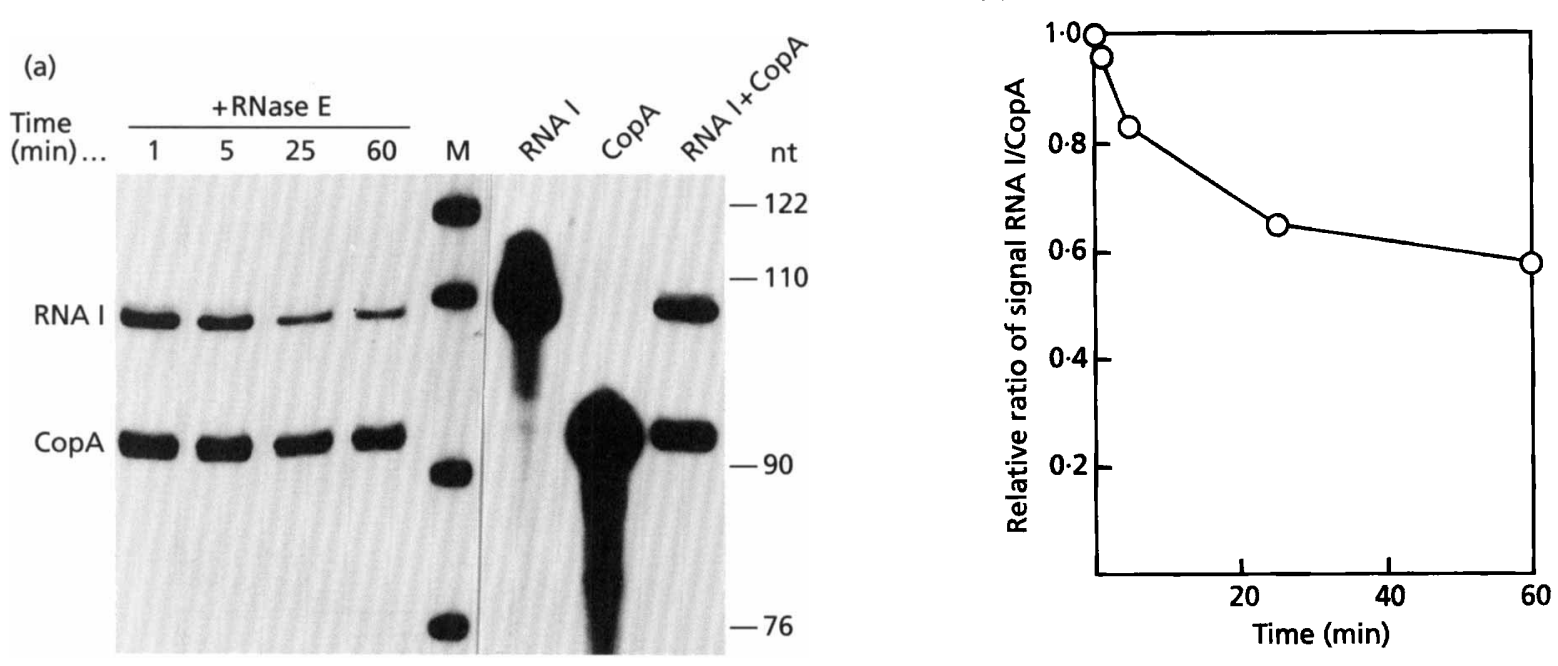

Fig. 7. Relative cleavage rates of RNA I and CopA by RNase E in vitro. Mixtures of 5'-end-labelled RNA I and CopA were subjected to RNase E cleavage. (a) Autoradiogram of the analysis. The gel was run so that the resulting small cleavage products are not visible. The times of sample withdrawal are indicated. The marker lane (M) represents $\mathrm{Mspl}^{-c l e a v e d}{ }^{32 \mathrm{P}}$ labelled pBR322 DNA. Lanes 'RNA I', 'CopA' and 'RNA I+CopA' are incubations of these RNAs in the absence of RNase E. (b) Phosphorlmager quantification of the RNA I and CopA band intensities in (a), represented as relative ratios of RNA I/CopA. The ratio of the intensities of the input RNAs (lane RNA I + CopA) was set to unity.

negative regulator RNA of the post-segregational killing system (hok/sok), is dependent on A-tailing by $\mathrm{PcnB}$ (Mikkelsen \& Gerdes, 1997). It is worth noting that the degree of SL-E stabilization obtained in the series of isogenic strains used in this study exceeds that seen in a different strain background (Söderbom et al., 1997). The activities responsible for this difference are not known.

Both exoribonucleases were able to degrade SL-E, indicated by stabilization in the absence of both functional enzymes (Fig. 3g). However, since some residual degradation occurred under these conditions, other enzymic activities must be able to partially replace the two major exoribonucleases. The relatively minor effects on apparent half-life of SL-E in the single mutant cases suggest that RNase II and PNPase can functionally replace each other (Fig. 3c, d). Both enzymes appear to require the presence of $\mathrm{PcnB}$ to promote SL-E decay. Inactivation of RNase II also revealed a different effect. SL-E was more stable at permissive than at nonpermissive temperature (Fig. 3c). The degree of stabilization was approximately threefold in three separate experiments and suggests that, when RNase II is present, the rate of PNPase-dependent SL-E degradation is decreased, i.e. since RNase II processivity is impeded by stable stem-loops (Guarneros \& Portier, 1991; McLaren et al., 1991), binding (or stalling) of this enzyme at the 3'stem-loop could protect SL-E from PNPase activity. Alternatively, RNase II could act by removing short Atails, converting the RNA into a less suitable substrate for PNPase. A similar RNase-II-dependent protection of RNA-OUT (Pepe et al., 1994) and rpsO mRNA (Hajnsdorf et al., 1994) was previously reported. The two effects of RNase II are indicated schematically in Fig. 8.
In conclusion, CopA decay most likely involves at least the four genes/gene products studied here, and the possible involvement of additional exonucleases is suggested by the pattern obtained in the $\mathrm{Exo}^{-}$strain. The steps in the degradation pathway of CopA are summarized in Fig. 8. Decay is initiated by RNase E, followed by PcnB action on SL-E (most likely via addition of short A-tails), which in turn is a prerequisite for rapid $3^{\prime}$-exonucleolytic degradation by PNPase and/or RNase II. Our data do not permit us to assess the relative contributions of these two latter enzymes.

The pathway of CopA decay is similar to that of RNA I and Sok, but shows some differences. RNase E cleavage is, in all three cases, required as the initial step (LinChao \& Cohen, 1991; Söderbom et al., 1997; Mikkelsen \& Gerdes, 1997), and PcnB activity (in RNA I and Sok: polyadenylation; Xu \& Cohen, 1995; Mikkelsen \& Gerdes, 1997) is needed to provide exoribonucleases with proper substrates. The degree of stabilization of the RNase-E-generated 3'-fragments SL-E (of CopA; twofold in $\triangle p c n B$; Söderbom et al., 1997) and RNA $\mathrm{I}_{-5}$ (of RNA I; > 10-fold; He et al., 1993; Xu et al., 1993; $\mathrm{Xu} \&$ Cohen, 1995) is however different. If we speculate that the effect in both cases is mediated by A-tails, this may indicate that longer tails or a higher stoichiometric fraction of tails must be added to RNA I than to CopA to permit exonucleolytic degradation. Since previous attempts to identify polyadenylated CopA species in vivo have failed (Söderbom et al., 1997; and unpublished), and the band patterns in Figs 1-3 do not indicate a significant degree of tailing, the question of whether PcnB affects CopA degradation directly or via its polyadenylation activity is still unresolved. 


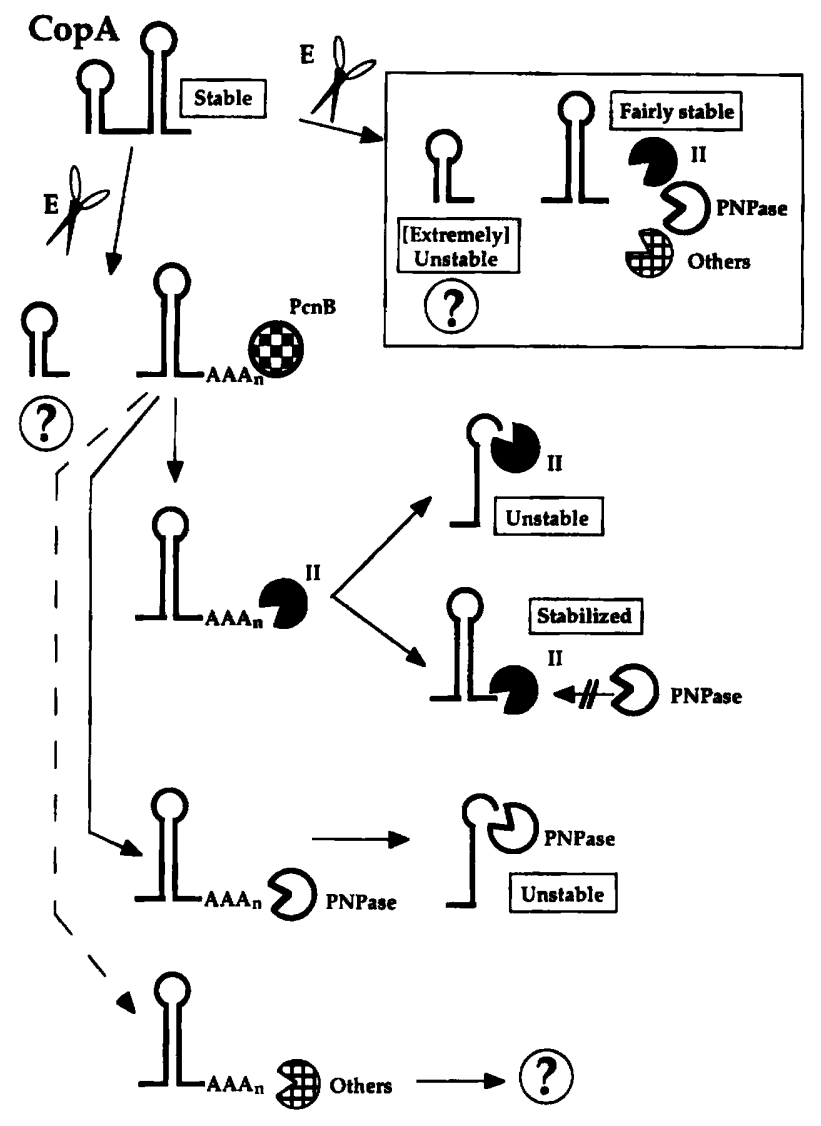

Fig. 8. Tentative pathway of CopA decay. Possible steps in the decay pathway of CopA are indicated and were based on the effects of mutations according to Figs 1-3 and previous work (Soderbom et al., 1997). Note that the putative role of PCnB in adding A-tails is indicated although the presence of polyadenylated CopA species has not yet been demonstrated (Soderbom et al., 1997). The two possible roles of RNase II are shown by a branch leading to either SL-E decay or to protection from PNPase (see Results for details). Question marks indicate that information about the identity of other enzymic activities ('others') or about the fate of intermediates is not available (5'-fragment of CopA). The box indicates the suggested stabilization of SL-E in the absence of PcnB.

Upon polyadenylation of RNA I, the degradation rate by PNPase is drastically increased both in vitro and in vivo (Xu \& Cohen, 1995), suggesting that this enzyme is the most important one in PcnB-dependent decay of RNA I I $_{5}$. Similarly, in vivo data suggest that PNPase is the most important exonucleolytic activity on Sok substrates (Mikkelsen \& Gerdes, 1997). In the case of CopA, a dominant role of PNPase is not supported, since the absence of this enzyme alone has only minor effects on CopA decay. Interestingly, results by $\mathrm{Xu} \&$ Cohen (1995) suggested that PNPase is also required for full RNase E activity on RNA I. RNase E activity was stimulated approximately sevenfold. Again, CopA decay is different in that no quantitatively comparable effect is supported (cf. Fig. 3a, d).

What are the possible reasons for the observed differences in decay rate and pathway of RNA I and CopA ? It is conceivable that RNA structure is important: RNA I may fold into a clover-leaf structure in which the $5^{\prime}$ - and $3^{\prime}$-ends are in close proximity. This might facilitate direct interaction between enzymes acting at either end, such as RNase E and PNPase, to mutually stimulate each other's activities. This may not be the case for CopA. Similarly, the length of the protruding 3 '-tail seems to be different: CopA has a longer template-encoded tail than RNA I and Sok ( six and two to three nucleotides, respectively). RNase II and PNPase require singlestranded extensions of sufficient length $3^{\prime}$ of stable RNA structures to initiate degradation, and polyadenylation is known to aid RNase II in degradation of otherwise resistant structures (Coburn \& Mackie, 1996a, b). Hence, CopA's longer tail may render polyadenylation quantitatively less important than in the case of RNA I (and possibly Sok). If so, this might also explain the difficulty of identifying A-tails on CopA (see above).

The overall decay rate of CopA is higher than that of RNA I (Xu et al., 1993; He et al., 1993; Söderbom et al., 1997). In spite of this, the RNase-E-generated CopA fragment SL-E is more abundant than RNA $I_{-5}$, in a steady state situation. This could suggest that RNase E cleaves CopA more rapidly than RNA I. When purified RNase E was used on CopA and RNA I as competing substrates, RNA I was more rapidly cleaved (Fig. 7). Since RNase E cleavage of RNA I previously had been shown to be stimulated by PNPase (Xu \& Cohen, 1995), this would imply that the relative rate difference observed is even underestimated. We suggest that additional proteins may affect the rate of RNase E cleavage of these RNAs in vivo, or, alternatively, that the structures of the RNAs in vitro are not identical to those in vivo.

A clear indication that RNase $\mathrm{E}$ activity is modulated by other factors present in vivo can be found in the identification of RNase $E$ cleavage sites on CopA in vitro (Figs 4-6). Two major cleavage sites were mapped. Both cleavages appear to occur independently, since bands consistent with these sites were found both when $5^{\prime}$ - and $3^{\prime}$-fragments were analysed. Neither one of these sites coincides precisely with the one mapped in vivo (Söderbom et al., 1997), which is located between the two scissions generated in vitro. Site E/ 1 conforms to the known preference of RNase E for A/U-rich, singlestranded RNA segments (McDowall et al., 1994), whereas $\mathrm{E} / 2$ does not, although it is used with equal efficiency. Similar discrepancies between in vitro and in vivo cleavages by $\mathrm{RNase} \mathrm{E}$ have been reported previously (Braun et al., 1996; Kaberdin et al., 1996; Naureckiene \& Uhlin, 1996), emphasizing the role of additional factors assisting RNase $\mathrm{E}$ in cleavage site selection in the cell. Hence, this endonuclease is still a 'wonderfully mysterious enzyme' (Cohen \& McDowall, 1997) and other factors that determine its cleavage site specificity remain elusive.

In conclusion, the complexity of CopA decay addressed in this communication is certainly underestimated. Additional proteins, possibly as part of the degrado- 
somal complex, are probably involved in fine-tuning of degradation activity. From our experience, in vivo analyses of decay in mutant host strains can yield useful information, but the uncertainties created by, for example, unwanted and unanticipated side effects such as altered regulation of one enzyme due to the absence of another (e.g. Zilhão et al., 1996)-make interpretations difficult. Reconstitution of complete degradosomal activities to obtain in vivo-like RNA decay in vitro (e.g. Py et al., 1996) should eventually result in a better understanding of RNA turnover.

\section{ACKNOWLEDGEMENTS}

This work was supported by the Swedish Natural Science Research Council/NFR and the Swedish Research Council for Engineering Sciences/TFR (E.G.H.W.). We thank Saule Naureckiene for purified RNase E, Kenn Gerdes for bacterial strains and plasmid pKG339, and S. Rosén for skilful technical help.

\section{REFERENCES}

Arraiano, C. M., Yancey, S. D. \& Kushner, S. R. (1988). Stabilization of discrete mRNA breakdown products in ams pnp $r n b$ multiple mutants of Escherichia coli K-12. J Bacteriol 170, 4625-4633.

Bertani, G. (1951). Studies on lysogenesis. I. The mode of phage liberation by lysogenic Escherichia coli. J Bacteriol 62, 293-300.

Blomberg, P., Wagner, E. G. H. \& Nordström, K. (1990). Control of replication of plasmid $\mathrm{R} 1$ : the duplex between the antisense RNA, CopA, and its target, CopT, is processed specifically in vivo and in vitro by RNase III. EMBO J 9, 2331-2340.

Brantl, S. \& Wagner, E. G. H. (1996). An unusually long-lived antisense RNA in plasmid copy number control: in vivo RNAs encoded by the streptococcal plasmid pIP501. J Mol Biol 255, 275-288.

Braun, F., Hajnsdorf, E. \& Regniér, P. (1996). Polynucleotide phosphorylase is required for the rapid degradation of the RNase E-processed $r p s O$ mRNA of Escherichia coli devoid of its $3^{\prime}$ hairpin. Mol Microbiol 19, 997-1005.

Cao, G. J. \& Sarkar, N. (1992). Identification of the gene for an Escherichia coli poly(A) polymerase. Proc Natl Acad Sci USA 89, 10380-10384.

Carpousis, A. J., Houve, G. V., Ehretsmann, C. \& Krisch, H. M. (1994). Copurification of E. coli RNAse E and PNPase: evidence for a specific association between two enzymes important in RNA processing and degradation. Cell 76, 889-900.

Coburn, G. A. \& Mackie, G. A. (1996a). Differential sensitivities of portions of the mRNA for ribosomal protein S2O to $3^{\prime}$ exonucleases dependent on oligoadenylation and RNA secondary structure. J Biol Chem 271, 15776-15781.

Coburn, G. A. \& Mackie, G. A. (1996b). Overexpression, purification, and properties of Escherichia coli ribonuclease II. $J$ Biol Chem 271, 1048-1053.

Cohen, S. N. \& McDowall, K. J. (1997). RNase E: still a wonderfully mysterious enzyme. Mol Microbiol 23, 1099-1106.

Deutscher, M. P. (1993). Ribonuclease multiplicity, diversity and complexity. J Biol Chem 268, 13011-13014.

Donovan, W. P. \& Kushner, S. R. (1986). Polynucleotide phosphorylase and ribonuclease II are required for cell viability and
mRNA turnover in Escherichia coli K-12. Proc Natl Acad Sci USA 83, 120-124.

Eguchi, Y., Itoh, T. \& Tomizawa, J. (1991). Antisense RNA. Annu Rev Biochem 60, 631-652.

Georgellis, D., Sohlberg, B., Hartl, F.-U. \& von Gabain, A. (1995). Identification of GroEL as a constituent of an mRNA protection complex in Escherichia coli. Mol Microbiol 16, 1259-1268.

Guarneros, G. \& Portier, C. (1991). Different specificities of ribonuclease II and polynucleotide phosphorylase in 3 'mRNA decay. Biochimie 73, 543-549.

Hajnsdorf, E., Braun, F., Haugel-Nielsen, J. \& Régnier, P. (1994). Polyadenylation destabilizes the $r p s \mathrm{O}$ RNA of Escherichia coli. Proc Natl Acad Sci USA 92, 3973-3977.

He, L., Soderbom, F., Wagner, E. G. H., Binnie, U., Binns, N. \& Masters, M. (1993). PcnB is required for the rapid degradation of RNA I, the antisense RNA that controls the copy number of ColE1-related plasmids. Mol Microbiol 9, 1131-1142.

Hjalt, T. Å. H. \& Wagner, E. G. H. (1995). Bulged-out nucleotides protect an antisense RNA from RNase III cleavage. Nucleic Acids Res 23, 571-579.

Ingle, C. A. \& Kushner, S. R. (1996). Development of an in vitro mRNA decay system for Escherichia coli: poly(A)polymerase I is necessary to trigger degradation. Proc Natl Acad Sci USA 93, 12926-12931.

Jensen, R. B., Grohmann, E., Schwab, H., Diaz-Orejas, R. \& Gerdes, K. (1995). Comparison of $c c d$ of F, parDE of RP4, and parD of R1 using a novel conditional replication control system of plasmid R1. Mol Microbiol 17, 211-220.

Kaberdin, V. R., Chao, Y. H. \& Lin-Chao, S. (1996). RNase E cleaves at multiple sites in bubble regions of RNA I stem loops yielding products that dissociate differentially from the enzyme. J Biol Chem 271, 13103-13109.

Lin-Chao, S. \& Cohen, S. N. (1991). The rate of processing and degradation of antisense RNA I regulates the replication of ColE1-type plasmids in vivo. Cell 65, 1233-1242.

Lopilato, J., Bortner, S. \& Beckwith, J. (1986). Mutations in a new chromosomal gene of Escherichia coli $\mathrm{K}-12, p c n B$, reduce plasmid copy number of pBR322 and its derivatives. Mol Gen Genet 205, 285-290.

McDowall, K. J., Lin-Chao, S. \& Cohen, S. N. (1994). A + U content rather than a particular nucleotide order determines the specificity of RNase E cleavage. J Biol Chem 269, 10790-10796.

Mclaren, R. S., Newbury, S. F., Dance, G. S., Causton, H. C. \& Higgins, C. F. (1991). mRNA degradation by processive $3^{\prime}-5^{\prime}$ exoribonucleases in vitro and the implications for prokaryotic mRNA decay in vivo. J Mol Biol 221, 81-95.

Masters, M., Colloms, M. D., Oliver, I. R., He, L., Macnaughton, E. J. \& Charters, Y. (1993). The pcnB gene of Escherichia coli, which is required for ColE1 copy number maintenance, is dispensable. J Bacteriol 175, 4405-4413.

Miczak, A., Kaberdin, V. R., Wei, C. L. \& Lin-Chao, S. (1996). Proteins associated with RNase $\mathrm{E}$ in a multicomponent ribonucleolytic complex. Proc Natl Acad Sci USA 93, 3865-3869.

Mikkelsen, N. D. \& Gerdes, K. (1997). Sok antisense RNA from plasmid R1 is functionally inactivated by RNase E and polyadenylated by poly(A) polymerase I. Mol Microbiol 26, 311-320. Naureckiene, S. \& Uhlin, B. E. (1996). In vitro analysis of mRNA processing by RNase $\mathrm{E}$ in the pap operon of Escherichia coli. Mol Microbiol 21, 55-68.

Nierlich, D. P. \& Murakawa, G. J. (1996). The decay of bacterial messenger RNA. Prog Nucleic Acid Res Mol Biol 52, 153-216. 
Nordström, K. \& Wagner, E. G. H. (1994). Kinetic aspects of control of plasmid replication by antisense RNA. Trends Biochem Sci 19, 294-300.

Pepe, C. M., Maslesa-Galic, S. \& Simons, R. W. (1994). Decay of the IS10 antisense RNA by $3^{\prime}$ exoribonucleases: evidence that RNase II stabilizes RNA-OUT against PNPase attack. Mol Microbiol 13, 1133-1142.

Py, B., Causton, H., Mudd, E. A. \& Higgins, C. F. (1994). A protein complex mediating mRNA degradation in Escherichia coli. Mol Microbiol 14, 717-729.

Py, B., Higgins, C. F., Krisch, H. M. \& Carpousis, A. J. (1996). A DEAD-box RNA helicase in the Escherichia coli RNA degradosome. Nature 381, 169-172.

Söderbom, F., Binnie, U., Masters, M. \& Wagner, E. G. H. (1997). Regulation of plasmid R1 replication: $\mathrm{PcnB}$ and RNase E expedite the decay of the antisense RNA, CopA. Mol Microbiol 26, 493-504.

Sohlberg, B., Lundberg, U., Hartl, F.-U. \& von Gabain, A. (1993). Functional interaction of heatshock protein GroEL - with an RNase E-like activity in Escherichia coli. Proc Natl Acad Sci USA 90, 277-281.
Wagner, E. G. H. \& Nordström, K. (1986). Structural analysis of an RNA molecule involved in replication of plasmid R1. Nucleic Acids Res 14, 2523-2538.

Wagner, E. G. H. \& Simons, R. W. (1994). Antisense RNA control in bacteria, phage and plasmids. Annu Rev Microbiol 48, 713-742.

Xu, F. \& Cohen, S. N. (1995). RNA degradation in Escherichia coli regulated by $3^{\prime}$ adenylation and $5^{\prime}$ phosphorylation. Nature 374 , 180-183.

Xu, F., Lin-Chao, S. \& Cohen, S. N. (1993). The Escherichia coli $p c n B$ gene promotes adenylation of antisense RNA I of ColE1type plasmids in vivo and degradation of RNA I decay intermediates. Proc Natl Acad Sci USA 90, 6756-6760.

Zilhão, R., Cairrao, F., Régnier, P. \& Arraiano, C. M. (1996). PNPase modulates RNase II expression in Escherichia coli: implications for mRNA decay and cell metabolism. Mol Microbiol 20, 1033-1042.

Received 15 January 1998; revised 6 March 1998; accepted 10 March 1998. 